CITATION: Tang, K.S. \& Rappa, N.A. (2020). The Role of Metalanguage in an Explicit Literacy Instruction on Scientific Explanation. International Journal of Science and Mathematics Education. doi: 10.1007/s10763-02010121-6.

\title{
The Role of Metalanguage in an Explicit Literacy Instruction on Scientific Explanation
}

\begin{abstract}
This paper illustrates the role of metalanguage in an explicit literacy instruction to talk about the forms and functions of scientific genres, particularly the genre of explanation. In the context of science, metalanguage refers to the technical terms for talking about scientific language using words like law, hypothesis, and evidence. Despite many efforts to use literacy strategies to address the challenges of learning scientific language, the conventional genres commonly found in science remain implicit in most science classroom teaching. In order to explicitly discuss the nature of scientific genres and how they are linked to scientific practices, scientific metalanguage provides a potential literacy tool. To illustrate this argument, we draw on a case study where four teachers and their grade nine students learned how to use a specific type of metalanguage to describe scientific explanation. Analysis of their classroom discourse showed that the use of the metalanguage facilitated explicit communication about the logical sequence, epistemic structure, and validity of scientific explanation. Based on the findings, we discuss the usefulness of metalanguage for teachers and students to describe and analyze scientific genres as well as how these genres are used to construct and communicate scientific knowledge.
\end{abstract}

Keywords: Language of science, literacy instruction, metalanguage, scientific explanation, genre 
CITATION: Tang, K.S. \& Rappa, N.A. (2020). The Role of Metalanguage in an Explicit Literacy Instruction on Scientific Explanation. International Journal of Science and Mathematics Education. doi: 10.1007/s10763-02010121-6.

\section{Introduction}

The unique features of scientific language pose significant challenges for most students in gaining access to scientific knowledge and practices (Lemke, 1990). With growing awareness of these challenges, there has been more emphasis on the use of literacy instruction in science classrooms over the last two decades (Pearson, Moje, \& Greenleaf, 2010). This emphasis toward subject-specific literacy is evident in many science curriculum standards and developments around the world (Tang \& Danielsson, 2018), which underscore the place for science teachers to use their "content area expertise to help students meet the particular challenges of reading, writing, speaking, listening, and language in their respective fields" (Council of Chief State School Officers, 2010, p. 3). As such, the importance of embedding literacy instruction within science classroom teaching and learning is wellacknowledged among education researchers and practitioners (Moje, 2007).

There have been a number of literacy-focused instructional approaches that provide exposure for students to various aspects of scientific language, such as vocabulary, oral and written discourse, reading comprehension, and visual/multimodal literacy (e.g., Gillies \& Baffour, 2017; Sørvik, Blikstad-Balas, \& Ødegaard, 2015; Wright, Franks, Kuo, McTigue, \& Serrano, 2016). However, one of the aspects missing from these approaches is the attention to the hidden conventions in science that govern the way language is used to produce and communicate scientific knowledge. These conventions are embedded within the genres of science, and while they are second nature to practicing scientists, they are foreign and unfamiliar to most students. A major problem in science education is the lack of a shared language among teachers and students to explicitly talk about the form and function in these genres and discuss how they are linked to the practice of science. What is needed is thus a metalanguage (language about language) to describe this aspect of scientific language. 
CITATION: Tang, K.S. \& Rappa, N.A. (2020). The Role of Metalanguage in an Explicit Literacy Instruction on Scientific Explanation. International Journal of Science and Mathematics Education. doi: 10.1007/s10763-02010121-6.

A metalanguage comprises a set of terminologies for discussing language functions and use (Basturkmen, Loewen, \& Ellis, 2002). In the context of English language learning, these terms include words like clause, verb, or conjunction used to indicate the grammatical functions and conventions of English. In the context of science, metalanguage refers to the technical terms for talking about scientific language, for example, words like law, hypothesis, and prediction. Scientific metalanguage differs from scientific vocabulary, which refers to content-specific concepts or ideas (Norris et al., 2008). Instead of discussing scientific content matter, metalanguage is useful to describe scientific genres, such as explanation, argument, information report, and experimental report. In a typical science classroom, teachers and students speak, read, and write these genres in almost every lesson. Not many science teachers and students can however accurately describe these genres in terms of their structure and linguistic expression (form) as well as why they are used and how they work (function). In other words, while teachers and students speak, read, and write scientific genres, they do not talk about the form and function of those genres. The conventions, structure, and expectations in these genres remain implicit and unspoken.

This paper aims to illustrate the role of metalanguage in an explicit literacy instruction on scientific explanation. What we mean by explicit in a literacy instruction is a deliberate and conscious discussion of the unspoken conventions, structure, and expectations embedded in scientific genres. Explicit instruction, contrary to a common misinterpretation, does not equate to a direct instruction of telling or lecturing. Thus, another aim of this paper is to highlight and discuss the difference between explicit literacy instruction using metalanguage and implicit literacy instruction without a metalanguage.

We start by presenting a theoretical argument for the use of metalanguage based on a review of studies on scientific language and literacy instruction, as well as a synthesis of two theoretical perspectives: one based on systemic functional linguistics (SFL) and the other 
CITATION: Tang, K.S. \& Rappa, N.A. (2020). The Role of Metalanguage in an Explicit Literacy Instruction on Scientific Explanation. International Journal of Science and Mathematics Education. doi: 10.1007/s10763-02010121-6.

based on research in science epistemology. We focus on metalanguage specific to the genre of scientific explanation and draw on a case study where the metalanguage was applied in several classrooms. Classroom video excerpts showing the use of this metalanguage before and after the teachers introduced the metalanguage were compared and analyzed. Analysis shows that the teachers and students used the metalanguage to talk about the sequence, structure, and validity of scientific explanation. Based on the findings, we discuss the usefulness of metalanguage to support explicit literacy instruction in science education.

\section{Perspectives on Scientific Language, Literacy \& Metalanguage}

\section{Scientific Language}

According to the theory of systemic functional linguistics or SFL, language is not merely a communicative tool that expresses preexisting thought, but it is a semiotic resource for making meaning of our experiences (Halliday \& Matthiessen, 2004). Language is thus a fundamental building block for constructing our thoughts and knowledge of the world (c.f. Vygotsky, 1986). As a meaning-making resource, scientific language has co-evolved with the historical development of scientific practice, and developed over time into a distinctive language variety suited for the production of scientific knowledge (Halliday, 1993). This historical evolution has made scientific language distinct from everyday use of language, not just in terms of the lexicon and writing style that are more visible, but also the embodiment of a subtle and underlying worldview, ideology, and value system (Gee, 2004). Learning science will undoubtedly involve learning the unique language of science (Lemke, 1990).

The features of scientific language can be examined at three levels - vocabulary (as word or phrase), grammar (as clause and sentence), and genre (as discourse). The majority of literacy instruction by content teachers tends to focus at the level of vocabulary and grammar, and consequently overlooks the role of genre in shaping scientific practices. In the current "practice turn" that places more emphasis on the nature of science (Ford, 2015), there is a 
CITATION: Tang, K.S. \& Rappa, N.A. (2020). The Role of Metalanguage in an Explicit Literacy Instruction on Scientific Explanation. International Journal of Science and Mathematics Education. doi: 10.1007/s10763-02010121-6.

renewed effort to align the language of science to the sociological practices employed by scientists as "they investigate and build models and practices about the world" (National Research Council, 2012, p. 30).

The intersection of language and scientific practices can be understood from the concept of genre. A genre is more than just a static text type or organization. It is also associated with the sociocultural activity and purpose in the production, distribution, and consumption of texts. Fairclough (1992, p. 126) defines genre as a "relatively stable set of conventions that is associated with, and partly enacts, a socially ratified type of activity". According to Martin (2007), a genre can be identified from its purpose and distinctive stages. First, a genre is organized around a common purpose of achieving a particular task with someone (e.g., buying things, doing an experiment). Second, achieving this purpose often involves several distinctive stages that have stable and predictable patterns of language use.

There are four major genres that are characteristic of scientific language: experimental report, informational report, argument, and explanation (Fang, Lamme, \& Pringle, 2010; Wellington \& Osborne, 2001). An experimental report includes the procedural steps as well as recount involved in conducting a scientific experiment. An information report organizes information, which can be descriptive or taxonomic, about things or events in the natural world. An argument presents a claim or position together with supporting or disputing evidence. Finally, an explanation accounts for the underlying causes or processes of a phenomenon. Past research has reported that many students faced difficulty in reading and writing scientific genres, largely because they are not familiar with the form and function of these genres (Fang et al., 2010).

\section{Research on Literacy Instruction in Science}

With an understanding of the challenges of scientific language, the integration of literacy instruction into mainstream science instruction has received greater attention in 
CITATION: Tang, K.S. \& Rappa, N.A. (2020). The Role of Metalanguage in an Explicit Literacy Instruction on Scientific Explanation. International Journal of Science and Mathematics Education. doi: 10.1007/s10763-02010121-6.

recent years (Yore, 2018). Numerous studies have been conducted to examine how science teachers conceive and enact literacy instruction in their teaching practice. (e.g., Bruna, Vann, \& Escudero, 2007; Wilson \& Jesson, 2018). It was found that most teachers had a narrow understanding of language at the simplest level of vocabulary. Consequently, they mainly emphasized science terminologies in their literacy instruction through a variety of strategies, such as repetition, morphemic analysis, phonological stress and pronunciation, and word wall. The sole attention to vocabulary can often be detrimental as many students mistake familiarity with scientific terms for knowledge of the concepts or processes related to the terms. This is because the emphasis on a key word tends to overshadow its associated semantic relationships and complex taxonomies, which often remain implicit in classroom discourse (Tang, 2019). This problem is particularly acute for emergent bilingual students in many schools in developed countries (Bruna et al., 2007).

While the focus on vocabulary in literacy instruction tends to be dominant in practice, a different approach focusing on reading- and writing-to-learn pedagogies is influenced or driven by education researchers (For a comprehensive review, see Pearson et al., 2010; Wright et al., 2016; Yang, Kuo, \& Jiang, 2020). Examples of these pedagogies include Seeds of Science, Roots of Reading (Barber, Pearson, \& Cervetti, 2006; Robertson \& Elliott, 2020), Concept-Oriented Reading Instruction (Brown \& Concannon, 2016; Guthrie, Wigfield, \& Perencevich, 2004), Science Writing Heuristic (Hand, Shelley, Laugerman, Fostvedt, \& Therrien, 2018), and Budding Science and Literacy Program (Sørvik et al., 2015).

Reading/writing-to-learn approaches are effective because they provide students with literacy opportunities (e.g., reading, writing, discussing, presenting) that are grounded in authentic contexts in conjunction with the use of appropriate instructional strategies to support their meaning making process. What is lacking in these approaches however is that the conventions and norms of scientific language, particularly its genres, remain unexamined 
CITATION: Tang, K.S. \& Rappa, N.A. (2020). The Role of Metalanguage in an Explicit Literacy Instruction on Scientific Explanation. International Journal of Science and Mathematics Education. doi: 10.1007/s10763-02010121-6.

in classroom texts, despite that students were given opportunities to read and engage with these texts (Schleppegrell, 2013). As this paper aims to show, it is important to make explicit the conventions of scientific genres, which can be achieved by means of metalanguage.

\section{Research on Metalanguage}

The role of metalanguage in science education was first researched by Norris and Phillips (1994), who saw its importance in learning the epistemology of science. Norris et al. (2008, p. 783) define scientific metalanguage as "terms for speaking about science (e.g., law, hypothesis, prediction, inference).” In their analysis of text features in commercial reading programs in Canada, they found that scientific metalanguage is infrequently used and emphasized, as compared to scientific vocabulary which are often highlighted. Scientific vocabulary are names that refer to specific scientific concepts, processes, or methods, such as density, heat capacity, evaporation, adaptation, distillation, and centrifugation. Scientific

metalanguage, by contrast, is the "language used to indicate how the propositions in scientific discourse are to be taken"; as facts, methods, results, justifications, or conjectures (Norris et al., 2008, p. 784). Only 11 terms from the analyzed texts in their study were found to speak metalinguistically about science, namely analyze, confirm, discover, experiment, justify, observation, principle, research, results, study, and test. Norris et al. (2008) thus argue that scientific metalanguage needs to be used more often during classroom instruction.

In another study, Shanahan (2012, p. 44) defines scientific metalanguage as a type of language used by the scientific community (e.g., scientists, teachers, journalists) to "analyze and describe the generation of scientific knowledge." This metalanguage (using words like claim, evidence, principle) is seldom used by scientists in their research work and communication, unless they are communicating to a general audience. However, it is a useful language for scientists to reflect on their own discourse, as a self-referential tool of one's own discourse. Furthermore, scientific metalanguage is often used by historians, philosophers, and 
CITATION: Tang, K.S. \& Rappa, N.A. (2020). The Role of Metalanguage in an Explicit Literacy Instruction on Scientific Explanation. International Journal of Science and Mathematics Education. doi: 10.1007/s10763-02010121-6.

sociologists of science to describe the nature of scientific work, and sometimes by science educators to teach the epistemic practices of science. In the latter aspect, specialized terms that describe scientific practices are essential to support teachers and students in deconstructing, analyzing, and critiquing scientific knowledge (Shanahan, 2012).

\section{Metalanguage of Scientific Explanation and other Genres}

As scientific language can be understood at three different levels: vocabulary, grammar, and genre, the metalanguage to describe scientific language can also be conceptualized at these levels as well. In this study, we will only focus on metalanguage at the level of genre. Drawing on SFL (e.g., Martin, 2007; Unsworth, 2001) and science epistemology research (e.g. Braaten \& Windschitl, 2011; Norris et al., 2008), we postulate that each of the four scientific genres is associated with a different set of metalanguage terms, as presented in Table 1.

Table 1. Metalanguage Terms Associated with Various Scientific Genres

\begin{tabular}{|c|c|c|c|c|}
\hline $\begin{array}{l}\text { Scientific } \\
\text { Genre }\end{array}$ & $\begin{array}{c}\text { Experimental } \\
\text { Report }\end{array}$ & $\begin{array}{c}\text { Informational } \\
\text { Report }\end{array}$ & Argument & Explanation \\
\hline $\begin{array}{l}\text { Metalanguage } \\
\text { Terms }\end{array}$ & $\begin{array}{l}\text { Aim, method, } \\
\text { procedure, } \\
\text { variable, } \\
\text { prediction, } \\
\text { hypothesis, test, } \\
\text { observation, data, } \\
\text { result }\end{array}$ & $\begin{array}{l}\text { Classification, } \\
\text { composition, } \\
\text { taxonomy, } \\
\text { attribute, } \\
\text { property, } \\
\text { comparison }\end{array}$ & $\begin{array}{l}\text { Claim, evidence, } \\
\text { justify, warrant, } \\
\text { rebuttal }\end{array}$ & $\begin{array}{l}\text { Principle, law, } \\
\text { model, theory, } \\
\text { concept, } \\
\text { reasoning, cause- } \\
\text { effect, sequence, } \\
\text { phenomenon }\end{array}$ \\
\hline
\end{tabular}

The associated metalanguage for experimental report is arguably the most apparent for many science teachers and students, through terms like aim, method, procedure, independent/dependent variable, observation, data and result. In many secondary school science curricula around the world, such metalanguage is typically taught and used during science practical where students are expected to perform an experiment and write a laboratory report of the results (Abrahams, Reiss, \& Sharpe, 2013). The metalanguage for informational report revolves around labels that describe the textual organization of scientific 
CITATION: Tang, K.S. \& Rappa, N.A. (2020). The Role of Metalanguage in an Explicit Literacy Instruction on Scientific Explanation. International Journal of Science and Mathematics Education. doi: 10.1007/s10763-02010121-6.

knowledge, such as classification, composition, and taxonomy. While linguists often use these terms to describe scientific texts, science educators typically do not use them to talk about an information report.

For the genre of argument, there have been several studies that examine the role of argumentation in science education (Cavagnetto, 2010). A common approach in these studies was the use of Toulmin's (1958) argument structure to identify the functional components of an argument such as claim, evidence, warrant, and rebuttal (e.g., Erduran, Simon, \& Osborne, 2004; Sampson, Grooms, \& Walker, 2011). The use of these terms (e.g., claim, evidence) essentially functions as a metalanguage to talk about the conventions in an oral or written scientific argument. The genre of explanation is often conflated with that of argument, even though it has a distinctive epistemological function (Osborne \& Patterson, 2011). This paper will focus on the metalanguage associated with scientific explanation.

A scientific explanation is a theoretical account of how or why a natural phenomenon occurs the way it does (Achinstein, 1983). There are three major characteristics in a scientific explanation, with each characteristic defined by the following metalanguage terms: premise, reasoning, and outcome. From the philosophy of science, the premise is a general statement that is developed and validated based on repeated observations, such as laws, or has the power to connect seemingly disparate phenomena in an unifying model or theory (Braaten \& Windschitl, 2011). The premise functions as the theoretical basis of an explanation and it can include definition, law, principle, model, theory, and concept. Reasoning is the logical chain of sequences that are caused by or derived from the premise. From a SFL perspective, this sequential chain is connected through the use of conjunctions, (e.g., and, next, thus). Lastly, the outcome is the phenomenon to be explained. Based on these three characteristics, the genre of scientific explanation can be described based on this metalanguage of premise (P), reasoning (R), and outcome (O), or simply PRO (Tang, 2016b). 
CITATION: Tang, K.S. \& Rappa, N.A. (2020). The Role of Metalanguage in an Explicit Literacy Instruction on Scientific Explanation. International Journal of Science and Mathematics Education. doi: 10.1007/s10763-02010121-6.

In sum, a review of the literature has shown there had been a number of literacyfocused instructional approaches that support students in overcoming the language barrier in learning science. However, there is still a gap in articulating the implicit language features (e.g., conventions) for students, particularly in the area of scientific explanation. The notion of a metalanguage that describes scientific language at the level of genre is postulated as a potential tool to enable a more explicit literacy instruction. Informed by this theoretical perspective, the study in this paper aimed to investigate the role of a metalanguage in enabling teachers and students to talk about scientific explanation during classroom teaching.

\section{Methodology}

\section{Research Context}

The case study in this paper draws on data from a larger research project that used design research (Collins, Joseph, \& Bielaczyc, 2004) to promote disciplinary literacy instruction in secondary school science classrooms. The research project took place in Singapore and it involved two physics teachers, two chemistry teachers, and 107 students from two public secondary schools. Each teacher selected one of their classes to be involved in the project. The academic abilities of these students were about average to above average based on national examination results taken at the end of sixth grade.

The research project comprised a pre-intervention phase where we observed the teachers' literacy practices over six months, followed by an intervention phase to co-develop and test teaching strategies and materials with the collaborating teachers for two years. One of the teaching strategies developed during the intervention phase was the PRO metalanguage. Through ongoing professional development workshops as part of the research project, the teachers then learned about PRO and discussed with the research team on applying it in their classes. They also designed every lesson based on a literacy-inquiry model that was anchored by an authentic and puzzling real-world phenomenon (See Tang \& Putra, 
CITATION: Tang, K.S. \& Rappa, N.A. (2020). The Role of Metalanguage in an Explicit Literacy Instruction on Scientific Explanation. International Journal of Science and Mathematics Education. doi: 10.1007/s10763-02010121-6.

2018). The use of PRO to construct a scientific explanation was thus embedded in an authentic learning context.

\section{Case Study \& Data Analysis}

For this study, we draw on an instrumental case study (Stake, 2000) to examine how the teachers adopted and integrated the PRO metalanguage in their classroom discourse. The research question that guided the study was: What was the literacy instruction used by the teachers to support students' construction of scientific explanation?

The purpose of case study is not to make universal claims or examine typicality about the use of literacy instruction, but to present "telling cases" (Mitchell, 1983) that reveal insights into the role of metalanguage as a practical literacy tool for science teaching and learning. Telling cases do not necessarily imply typicality. Instead, they are selected to highlight how metalanguage was integrated into the teachers' classroom practices as well as what makes it an explicit form of literacy instruction, in contrast to an implicit one.

The main data source for this study consisted of classroom videos captured during the design research project. We first viewed and partitioned the videos according to Erickson's (1992) ethnographic microanalysis. The continuous video data were segmented into discrete “episodes" by identifying boundaries whenever there were shifts in the participants" interaction structure (e.g., whole-class talk to small group discussion) or the topic of discussion. For the purpose of this case study, we then selected episodes that revolved around the discussion of a scientific explanation, which typically involved asking a "how" or "why" type of question (Achinstein, 1983). We also made a distinction between episodes that occurred during the pre-intervention and intervention phases, so that a comparison could be made in terms of how the PRO metalanguage mediated classroom discourse. In total, 44 episodes (3 hours, 6 minutes) and 41 episodes ( 3 hours, 42 minutes) of classroom videos during the pre-intervention and intervention phases respectively were selected and analyzed. 
CITATION: Tang, K.S. \& Rappa, N.A. (2020). The Role of Metalanguage in an Explicit Literacy Instruction on Scientific Explanation. International Journal of Science and Mathematics Education. doi: 10.1007/s10763-02010121-6.

The next phase of analysis involved transcribing every selected episode and examining every utterance (as a turn-taking move) made by the participants using discourse analysis informed by micro-ethnography (Garcez, 2017) and SFL (Martin \& Rose, 2007). First, we identified the discursive moves based on the interactive function of each utterance, such as a question, statement, comment, or request (Chin, 2006). This analysis was necessary because the meaning of an utterance depends on the purpose for which it was raised within its dialogic context. Second, aligned with the analytical focus on scientific explanation, we examined how the logical sequence of an explanation was developed through the moment-bymoment utterances made by the participants. These logical sequences were typically constructed through the use of conjunctions (e.g., and, because, however) and verbal prompts asked by teachers (e.g., What would be the next answer? And then?). We also coded every statement in the explanation as premise $(\mathrm{P})$, reasoning $(\mathrm{R})$, or outcome $(\mathrm{O})$ according to the PRO framework.

Both authors discussed and confirmed one another's interpretation throughout the coding process. We discussed and resolved any ambiguity collectively, and this process often involved modifying the emerging claim and interpretation, until a common consensus was established. Another important aspect of validity is the attention to the micro-analytical details of the participants' speech and actions (Gee, 2010). The purpose of these details is to generate a "thick description" and add a layer of transparency for others to evaluate and thus ascertain the credibility of our interpretation as well as its applicability in their context (Denzin, 2002). This thick description is an important element of a case study as it generates insights that take into account the situated complexity of classroom interaction, instead of producing decontextualized claims. 
CITATION: Tang, K.S. \& Rappa, N.A. (2020). The Role of Metalanguage in an Explicit Literacy Instruction on Scientific Explanation. International Journal of Science and Mathematics Education. doi: 10.1007/s10763-02010121-6.

\section{Findings}

The episodes presented in this section illustrate how the teachers and students used the PRO metalanguage as a literacy instruction to talk about the sequence and structure of a scientific explanation, which were the unspoken conventions emphasized by the teachers. Within the space constraint of this paper, three episodes are selected to present a coherent account of how the PRO metalanguage was used. The first episode shows a typical literacy instruction that focused on scientific explanation before the teachers and students learned the PRO metalanguage. This episode, which occurred during the pre-intervention phase, provides an initial comparison with subsequent episodes when the metalanguage was used. During the intervention phase, two episodes are selected for the illustration for two reasons. First, they are representative of the various ways the teachers used PRO to engage their students in whole-class discussion. Second, they occurred at two different stages during the intervention - a beginning stage when the students were still learning the metalanguage and a later stage when they were more familiar with the metalanguage and its application. Both episodes therefore present a narrative of how the PRO metalanguage was learned and adapted chronologically.

\section{Episode 1: Literacy Instruction before PRO}

This episode in a physics class typifies how the four participating teachers engaged in a class discussion with their students before the PRO metalanguage was introduced. The episode occurred in a physics lesson on the relationship between pressure and volume of a gas. Like many science teachers, the teacher in this lesson used an Initiate-ResponseFeedback (IRF) interaction structure to elicit some ideas from the students (Mortimer \& Scott, 2003) in order to form the explanation for why pressure increases when volume decreases while temperature remains constant. Besides this IRF interaction, another common literacy instruction stressed on several linguistic considerations in framing an explanation, as 
CITATION: Tang, K.S. \& Rappa, N.A. (2020). The Role of Metalanguage in an Explicit Literacy Instruction on Scientific Explanation. International Journal of Science and Mathematics Education. doi: 10.1007/s10763-02010121-6.

shown in the following transcript. In all transcripts that follow, verbal phrases that are bold were used to inform our interpretation of the literacy instruction:

\begin{tabular}{|c|c|c|}
\hline Line & Participant & Utterance \\
\hline 1 & Teacher & $\begin{array}{l}\text { Okay, this is what is happening alright? The number of molecules do not change. But } \\
\text { the per unit volume, suddenly because of the compressed volume. So now, we have } \\
\text { more. More of them in one small area. Okay, let's move on... } \\
\text { Chelsea, what would be the next answer? }\end{array}$ \\
\hline 2 & Chelsea & Air molecules bombard.. more vigorously \\
\hline 3 & Teacher & $\begin{array}{l}\text { Air molecules, again the key word come out. Again, bombard, inner wall more } \\
\text { vigorously and more frequently. Notice the same word keep coming out, more } \\
\text { frequently. Alright, Chelsea, can you choose another person please? }\end{array}$ \\
\hline 4 & Chelsea & Margaret \\
\hline 5 & Teacher & Margaret, naturally the next answer would be?... \\
\hline 6 & Teacher & $\begin{array}{l}\text { Okay, realise that when we want to describe about pressure, the same thing would } \\
\text { happen again. Especially when we know pressure increases right, then we know the air } \\
\text { molecules must bombard more vigorously and more frequently. After that, the average } \\
\text { force... would increase. And then we relate it back to its formula. Pressure is force per } \\
\text { unit area, which is the definition of pressure. And then so pressure increases. There is } \\
\text { always a standard way of flow. }\end{array}$ \\
\hline
\end{tabular}

This episode highlighted two aspects of literacy instruction deemed important to the participating teachers. The first aspect was the attention to vocabulary or keywords (line 3), which was typical of many science teachers who are conscious of the role of literacy in science (Wilson \& Jesson, 2018). The second aspect is the flow of constructing a scientific explanation, which could be seen from the teacher's comments, such as "next answer" (line 1 \& 5) and "always a standard way of flow" (line 6). These two emphases on keywords and the flow of explanation was a recurring theme not only during class discussion, but also in scaffolding the students' writing. Interviews with the participating teachers at the beginning of the project corroborated that keywords and explanation flow were the two most important literacy instructions emphasized in their classrooms (for details, see Tang, 2016a).

The "standard way of flow" highlighted by the teacher is telling because it shows that the teacher was somewhat aware that a scientific explanation genre consists of a causal and temporal sequence of events (Unsworth, 2001). Although this teacher had made an effort to include this aspect of scientific explanation in his literacy instruction, it remained an implicit 
CITATION: Tang, K.S. \& Rappa, N.A. (2020). The Role of Metalanguage in an Explicit Literacy Instruction on Scientific Explanation. International Journal of Science and Mathematics Education. doi: 10.1007/s10763-02010121-6.

instruction because the instruction did not evoke, discuss, or bring to surface the unspoken conventions of the genre (Andringa, de Glopper, \& Hacquebord, 2011). By contrast, the next two episodes will illustrate explicit literacy instruction on scientific explanation through the application of the PRO metalanguage,

\section{Episode 2: Making Explicit the Logical Sequence and Structure of Explanation Genre}

This episode occurred in a chemistry class when the students had just been introduced to the PRO metalanguage one week earlier. The teacher was discussing with her students the process of constructing an explanation with the PRO metalanguage. The question that sparked the explanation was, "explain why potassium chloride can conduct electricity in molten state but not in solid state." The teacher used a literacy activity called jumbled sequence to scaffold the students' explanation. In this activity, the sequences of a written explanation was printed on numerous paper strips, and every pair of students had to rearrange them in a logical deductive order (from general to specific). The conjunctions in the passage were removed so that students would rearrange based on a logical sequence instead of analyzing the grammatical relationships of the conjunctions. After the students had completed this activity, the teacher nominated a pair of students to show their order of sequence to the class through a projector. As shown in the order of the strips from top to bottom in Figure 1, some of their sequences were incorrect (i.e. not deductive). The written numbers show the correct order.

The teacher later used Figure 1 to engage in a discussion with the class on the correct sequencing. (The numbering next to the strips in Figure 1 were written after the discussion). The following excerpt was drawn from this discussion:

\begin{tabular}{lll}
\hline Line & Participant & Utterance \\
\hline 1 & Teacher & Okay, alright, very quickly, can you alert me which one is the principle? Jessica? \\
& & Which statement? Can you read out for us? Which one do you think is the principle? \\
& & That means tell me something about the structure and the bonding. \\
2 & Jessica & No mobile ions \\
3 & Teacher & There are no mobile ions? \\
\hline
\end{tabular}


CITATION: Tang, K.S. \& Rappa, N.A. (2020). The Role of Metalanguage in an Explicit Literacy Instruction on Scientific Explanation. International Journal of Science and Mathematics Education. doi: 10.1007/s10763-02010121-6.

\begin{tabular}{|c|c|c|}
\hline 4 & Jessica & No, no, ions can move freely. \\
\hline 5 & Teacher & $\begin{array}{l}\text { "Ions can move freely". Alright, what is this for? Maybe we start from behind, } \\
\text { maybe it is easier? If we start from observation, can you tell me which one is an } \\
\text { observation? }\end{array}$ \\
\hline 6 & Jessica & Can conduct electricity \\
\hline 7 & Teacher & $\begin{array}{l}\text { Can conduct electricity in molten state. This is an observation, yah? Anymore } \\
\text { observation from here? No? What about the main reason for conducting electricity? }\end{array}$ \\
\hline 8 & Jessica & Ions can conduct electricity \\
\hline 9 & Teacher & Ah, ions can conduct electricity, so this is a reason, what else? Or there's nothing else? \\
\hline 10 & Jessica & Move freely \\
\hline 11 & Teacher & $\begin{array}{l}\text { Ions can move freely, any other reasons? You see, my main idea is I want to conduct } \\
\text { electricity, so what is the reason? The reason is because there is free mobile ions, } \\
\text { alright? What about the rest of them, when I talk about "strong electrostatic forces of } \\
\text { attraction", "oppositely charged ions", what are they? In principle, what they are, } \\
\text { the structure, the bonding itself. So the bonding is the "strong electrostatic forces of } \\
\text { attraction', alright, and "oppositely charged ions are held less tightly together". Okay, } \\
\text { so let's take a look and see whether or not we have it in the correct sequence. }\end{array}$ \\
\hline
\end{tabular}

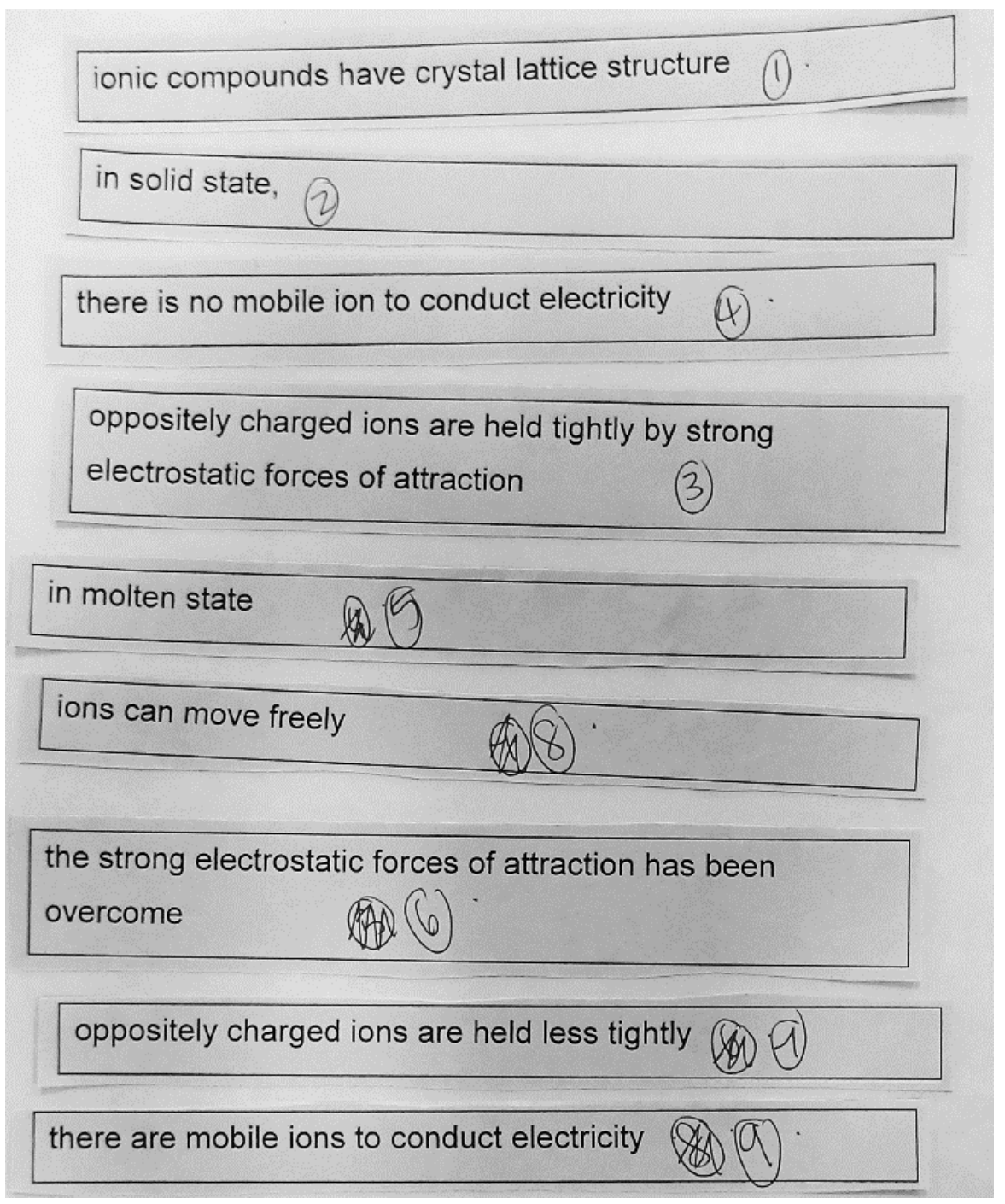

Figure 1. Sequence of an explanation arranged by two students 
CITATION: Tang, K.S. \& Rappa, N.A. (2020). The Role of Metalanguage in an Explicit Literacy Instruction on Scientific Explanation. International Journal of Science and Mathematics Education. doi: 10.1007/s10763-02010121-6.

As seen from the transcript (especially the phrases in bold), the teacher used the PRO metalanguage to mediate the discussion. First, she asked the students in line 1 to identify the principle $(\mathrm{P})$ in the explanation, which in this case was based on "the structure and the bonding." (During the research, the teachers used the term principle instead of premise as the term was deemed easier for the students to understand). This approach did not help the student Jessica as she incorrectly identified the principle twice in line 2 and 4 . Noticing Jessica's difficulty, the teacher then tried a different approach, which was to "start from behind" and asked "which one is an observation" $(\mathrm{O})$. By changing the order and identifying O (line 6), Jessica was then able to construct the sequence by linking to the reason $(R)$ in line 8-10 and eventually to the principle (P) as summarized by the teacher in line 11 . This implies that the reverse order - inductive (from $\mathrm{O}$ to $\mathrm{P}$ ) instead of deductive - was easier for Jessica to follow. Therefore, this episode shows how the PRO metalanguage was used by the teacher to support Jessica's reasoning.

Comparing this episode with the previous one before the use of the PRO metalanguage, we can see the role of the metalanguage in supporting an explicit literacy instruction. First, prior to the use of the metalanguage, the default way of teaching a scientific explanation was to construct it from the beginning to the end in a linear and deductive sequence. There was no way for the teachers to indicate what were considered the "beginning" and "end" of an explanation and how they were connected logically, except through vague and implicit expressions of a linear sequence, such as "let's start with", "the next answer", or "standard way of flow", as we saw in episode 1. Interestingly, the use of the jumbled sequence literacy activity before this discussion took place was also an implicit way of emphasizing the linear sequence of a scientific explanation. With the use of metalanguage in this episode, the beginning and end of an explanation now had defined labels (e.g., principle, observation) that were learned and adopted by every member in this class. Using 
CITATION: Tang, K.S. \& Rappa, N.A. (2020). The Role of Metalanguage in an Explicit Literacy Instruction on Scientific Explanation. International Journal of Science and Mathematics Education. doi: 10.1007/s10763-02010121-6.

these labels as navigational markers for different stages of the explanation, the teacher could thus guide Jessica to construct the explanation in a reverse order from "observation" to the "reason" and eventually to the "principle."

In addition, these labels served more than just a naming convention to indicate the "beginning" and "end" of an explanation; they also had meanings with regard to the epistemic structure of a scientific explanation. The purpose of a scientific explanation is to provide an account of a natural phenomenon based on an accepted theory or model. Thus, the functions of the "beginning" and "end" of an explanation are to provide the basis of the account from theory to the phenomenon, and these meanings are captured in the terms "premise" and "outcome" respectively (or "principle" and "observation" in the case of this episode). As the students had learned these meanings within the PRO metalanguage, they could see more explicitly the structure of a scientific explanation and how the explanation was connected from principle to observation. Conversely, they could also see how to reverse the order of the explanation backward from observation to principle, which is opposite to the typical sequence of explaining from principle to observation (general to specific).

The explicit literacy instruction illustrated in this episode revolved around the genre of scientific explanation in terms of its logical sequence. This instruction was explicit because there was a discussion of how the sequence was determined by the stages and structure of the explanation, with a knowledge that each stage was related to different epistemic parts of a scientific explanation (e.g., premise, reasoning). As we saw in this episode, this discussion was facilitated by using the PRO metalanguage, which provided a form of shared language for the teacher and students to understand one another as they talked about the explanation.

\section{Episode 3: Making Explicit the Validity of Explanation Genre}

This episode in a physics class occurred six months into the design research intervention and the students had learned and applied the PRO metalanguage for a number of 
CITATION: Tang, K.S. \& Rappa, N.A. (2020). The Role of Metalanguage in an Explicit Literacy Instruction on Scientific Explanation. International Journal of Science and Mathematics Education. doi: 10.1007/s10763-02010121-6.

topics, including forces, density, and rotational moment. In this lesson on kinetic model of matter, a student asked a question on "why hot air rises?" The teacher then used this question for a whole-class discussion. Similar to his previous approach observed in earlier lessons, he first established the premise and outcome of the explanation, and then proceeded to unpack the reasoning:

\begin{tabular}{|c|c|c|}
\hline No & Participant & Utterance \\
\hline 1 & Teacher & $\begin{array}{l}\text { Okay, so (wrote "Due to kinetic model of matter" on the board). So this is my P. I have } \\
\text { already stated my P and my O. The problem now is to form the flow of reasoning. Or the } \\
\text { logical flow of reasoning. Now then what question would you ask yourself to form this } \\
\text { logical flow of reasoning? I already have density decreases... }\end{array}$ \\
\hline 2 & Nguyen & $\begin{array}{l}\text { I was thinking of the comparison between the density of the cool air and the density of hot } \\
\text { air. So when you compare, hot air will rise because lesser density. Normally when you } \\
\text { compare, you will say the denser one will sink... (class sneered cheered and interrupted) } \\
\text { I was thinking of comparing the normal air density and the hot air density. So when you } \\
\text { compare, normally you always say the denser one will sink. So since hot air rises, means the } \\
\text { density of the hot air is lower than the density of the normal air. Since normal air is having, is } \\
\text { denser. So it will sink. So when it sinks, the hot air rises due to the density is lower. It's like } \\
\text { you compare with a liquid and a cork... (class laughed and interrupted) } \\
\text { The bottle cork. So when you see the example where you take the water as the. So the cork } \\
\text { will always float due to the lower density. When you take the metal piece and put inside, it } \\
\text { will sink because it has a larger density (Alan raised his hand to speak) as compared to the } \\
\text { cork. }\end{array}$ \\
\hline 3 & Teacher & $\begin{array}{l}\text { Okay, that's his reasoning right. So his main point is that. Ultimately his main point is, he } \\
\text { straightaway think of the outcome, hot air rises. Then after that he.. (pointing to Alan) hold on } \\
\text { uh. He think for himself there must be something that causes it to rise or sink, and that is due } \\
\text { to density difference... but before density decrease, how do you explain density decreases? }\end{array}$ \\
\hline 4 & Mark & I think you have to ask yourself what... (inaudible) \\
\hline 5 & Teacher & (Pointing to Mark) I'm very sorry, but Alan wants to say something first. (Looking at Alan) \\
\hline 6 & Alan & What's his principle? What's his principle behind all his explanation? \\
\hline 7 & Teacher & Yah, it's already stated here (Pointed to the written $P$ ) \\
\hline 8 & Rhoda & But it's not related to.. \\
\hline 9 & Farid & Its not link to any principle \\
\hline 10 & Teacher & $\begin{array}{l}\text { Correct, he has another principle. Do you know what's the principle he was talking about } \\
\text { just now? }\end{array}$ \\
\hline 11 & Class & Density difference \\
\hline 12 & Teacher & Yes, density difference. That was his principle. Now Jay you were saying something? \\
\hline 13 & Jay & If you want to reason, you have to ask why does the density decrease, then go backward. \\
\hline
\end{tabular}

After the teacher's prompting in line 1, Nguyen began to give a rather elaborated explanation in line 2, with a sound reasoning based on density difference as the cause of an object's rise or fall. The elaborated explanation created quite an impression from his peers, as evident from the frequent cheering and interruption he received (unusual for this class as they 
CITATION: Tang, K.S. \& Rappa, N.A. (2020). The Role of Metalanguage in an Explicit Literacy Instruction on Scientific Explanation. International Journal of Science and Mathematics Education. doi: 10.1007/s10763-02010121-6.

tended to give short responses). In particular, Nguyen was able to: (a) make a long sequence of causal connections, (b) join the sequences with appropriate conjunctions (e.g., when, so, because) and (c) use a fitting analogy (cork and liquid) for comparison. Despite this feat, a number of students were able to identify a gap in his explanation. Even before Nguyen completed his explanation, Alan raised his hand, which from line 6, we can see his intention was to raise an objection that Nguyen's explanation did not have a premise. Then Rhoda and Farid also joined in to point out that Nguyen's explanation was not related to any premise (line 8-9). In their evaluations, we can see how the metalanguage mediated their critique of Nguyen's explanation.

From these evaluations, the validity of Nguyen's explanation was thus surfaced. Using the PRO metalanguage, they subsequently discussed two different premises, and this was followed by a discussion centered on why one premise (density difference) was superseded by the other premise (kinetic model of matter). By naming and articulating these two premises explicitly, they could also discuss why Nguyen's explanation, which was based on the premise of density difference (line 10-11), was not sufficient to complete the explanation. This was best illuminated by Jay in line 13 who saw the need to "go backward" further in the reasoning process from the premise of density difference to a more fundamental premise, which was the kinetic model of matter. Jay's response provided evidence that he understood the importance of asking questions exhaustively until he arrived at the premise (or "first cause"), such that he could no longer question or explain further. As Jay could still come up with a question on why density decreases, he knew that the premise could not be density difference as suggested by Nguyen,

What was being made explicit in this episode revolved around the validity of a scientific explanation. In particular, whether an explanation is valid or not is not determined by a model answer or a "standard way of flow", which students in Singapore were quite used 
CITATION: Tang, K.S. \& Rappa, N.A. (2020). The Role of Metalanguage in an Explicit Literacy Instruction on Scientific Explanation. International Journal of Science and Mathematics Education. doi: 10.1007/s10763-02010121-6.

to (see episode 1 for example), but rather by the connection to a fundamental and accepted premise. This episode demonstrated what the students could do when they applied the PRO metalanguage to evaluate a peer's explanation, even though his explanation was already sound by most measures. With the metalanguage, the students now had the language to explicitly make reference to genre as they reflected on and critiqued their construction of scientific explanation. Thus, they could evaluate an explanation according to its genre and the basis of a valid premise.

\section{Discussion of Findings}

This case study shows the role of a metalanguage in facilitating the discussion of the unspoken conventions involved in scientific language, particularly the genre of scientific explanation. Without a metalanguage, the emphasis on the language and literacy aspects of science tends to center on vocabulary and causal/temporal sequencing of explanation, as exemplified in episode 1 and consistent with what has been reported in the literature (e.g., Bruna et al., 2007, Wilson \& Jesson, 2018). Although the teachers in the case study knew about the importance of sequencing an explanation, how the sequencing was carried out was rather implicit through cues like "what is the next answer?" or "there must be a standard flow." There was no overt or explicit discussion on the rationale or logic of the sequencing.

When the PRO metalanguage was introduced, we saw two instances of how the teachers adapted and integrated the metalanguage into their classroom discourse at two different stages during the design research intervention. Initially, when the teachers and students were using and learning PRO for the first time, the emphasis then was to identify the premise/principle, reasoning, and outcome from various statements in an explanation, for example, through the jumbled sequence activity illustrated in episode 2 . At this stage, the PRO metalanguage was used to identify specific content knowledge (e.g., principle is "about the structure and the bonding"), rather than emphasizing a more general epistemic process 
CITATION: Tang, K.S. \& Rappa, N.A. (2020). The Role of Metalanguage in an Explicit Literacy Instruction on Scientific Explanation. International Journal of Science and Mathematics Education. doi: 10.1007/s10763-02010121-6.

involved in scientific explanation, such as its reasoning or validity. Nevertheless, the metalanguage at this stage was crucial for the teachers and students to identify and navigate the different parts of an explanation in relation to its structure, instead of merely sequencing it from the beginning to the end (from general to specific). The identification and labeling of the different parts subsequently allowed the explanation to develop in a reverse order, for instance when the teacher asked, "If we start from observation" (conduct of electricity) and linking it to the immediate "reason" of free moving ions, and eventually to the principle of molecular bonding. As we saw in episode 2, this approach was more helpful for the student.

When PRO was used across different topics over the year, the students began to see its relevance and application across different topics. Consequently, episode 3 showed how the emphasis of the metalanguage began to shift toward non-content specific matters, such as the discussion on scientific reasoning and validity. Notably, there was a discussion on how the basis of reasoning in an explanation centered on the role of a premise as the "first cause" that one would arrive at by asking questions retrospectively, until no further question can be asked anymore. This aspect of reasoning was demonstrated by several students when they challenged their peer's explanation for lacking a principle (by Alan, line 6), not linking to the established principle (by Rhoda and Farid, line 8-9), and the possibility of asking further questions (by Jay, line 13). The ensuing discussion brought to the surface the unspoken logic, structure, and convention that were embedded in scientific explanation.

The three episodes shown in this case study also collectively provided an illustrative example of what an explicit literacy instruction for a scientific explanation looked like. As discussed earlier, a scientific explanation involves a number of language features (e.g., causal or temporal sequences, generalizable principles or concepts). Many science teachers have implicit content knowledge about these language features. This content knowledge accounts for how they are able to assess and correct the scientific accuracy or completeness of a 
CITATION: Tang, K.S. \& Rappa, N.A. (2020). The Role of Metalanguage in an Explicit Literacy Instruction on Scientific Explanation. International Journal of Science and Mathematics Education. doi: 10.1007/s10763-02010121-6.

student's explanation, through instructions such as verbal questioning (e.g., "and then?") or stressing the concepts and keywords involved. Although such instructions point toward the language features of an explanation, we argue that they are implicit because they do not articulate the rationale and practices underpinning the literacy task of constructing an explanation. An explicit literacy instruction, on the other hand, involves a deliberate and conscious discussion of the hidden conventions and expectations that are embedded in the scientific practice of constructing an explanation, as well as other genres in general.

As shown in this study, to enable an explicit discussion of scientific explanation would require the teachers and students to first deliberately learn a metalanguage in order to talk about the nature of an explanation. This metalanguage (e.g., premise, principle, reasoning, outcome), being distinctively different from the usual scientific vocabulary in the curriculum, would take some time for the teachers and students to get used to. Thus, there was a deliberate effort to introduce the metalanguage and reinforce it several times during various instructional activities, with episode 2 shown as a representative example. Once the teachers and students became more familiar with the metalanguage, they could then begin to discuss how a scientific explanation works by talking and critiquing the relationships among the various epistemic components, as we saw in episode 3.

Lastly, this study shows that an explicit literacy instruction does not always imply lecture or direct instruction. Instead, it can be embedded in an authentic context of learning science through an exploration or investigation of real-world phenomena, as was the case in this research intervention. In other words, explicit literacy instruction and scientific inquiry are not mutually exclusive.

\section{Limitations of Study}

In this study, although the findings suggest that the teachers and students had developed a greater awareness of the structure and purpose of a scientific explanation by 
CITATION: Tang, K.S. \& Rappa, N.A. (2020). The Role of Metalanguage in an Explicit Literacy Instruction on Scientific Explanation. International Journal of Science and Mathematics Education. doi: 10.1007/s10763-02010121-6.

learning its metalanguage, more could be done to facilitate their epistemic understanding of a scientific explanation as embedded in the nature of science. For example, while some students understood the validity of an explanation rests on a fundamental premise (or first cause) that cannot be explained any further, it is important to stress that the premise itself can be questioned in light of supporting or contradictory evidence. However, this will require scientific argumentation - a different practice mediated by a different metalanguage (e.g., claim, evidence, rebuttal) that was not emphasized during the study.

Another constraint in this study is the school system that predominantly focuses on coverage of content knowledge and high stakes examinations, which is typical in many countries. As whole class talk tends to be teacher-dominated (e.g. episode 1 and 2), capturing students' voices and reasoning in the talk is often difficult. The extended discussion in episode 3 was a rare moment where the students spoke longer than the teacher. We cannot infer whether the increased students' voices was due to the use of the metalanguage or other contextual factors. Nevertheless, the authoritative classroom environment does not invalidate the findings from this case study as its purpose was not to make generalizable claims but to illuminate how an explicit literacy instruction looked like within the situated and contextual reality of a science classroom.

\section{Implications \& Future Research}

This study has several implications for classroom instruction and teacher education. One notable distinction highlighted in this paper is the difference between "talking the genres" versus "talking about the genres." Past research has found that science teachers spend a significant amount of classroom time describing and explaining scientific phenomena, mostly through talk but also incorporating other literacy activities such as reading, writing, and drawing (Tang, 2016a; Wilson \& Jesson, 2018). In other words, teachers are often talking the genres of informational report and scientific explanation, but not about the form and 
CITATION: Tang, K.S. \& Rappa, N.A. (2020). The Role of Metalanguage in an Explicit Literacy Instruction on Scientific Explanation. International Journal of Science and Mathematics Education. doi: 10.1007/s10763-02010121-6.

function of those genres. To talk about the genres will involve a discussion about its form (e.g., nature, structure) and function (e.g., purpose, expectation). This discussion rarely occurs in most science classroom instruction ${ }^{1}$. A key implication from this study is that talking about the genres will involve the use of a metalanguage, which is particularly useful in helping students understand the epistemology of science.

Although this study only focused on the genre of explanation, we can draw a similar implication to other scientific genres and how those genres relate to the nature of science. As discussed earlier, Table 1 presented a set of metalanguage terms that are associated with each of the four scientific genres.-It will be useful to conduct more research to validate and investigate the impact of using these terms as metalanguage to support students in learning about the scientific practices of interpreting and writing experimental reports, communicating scientific information, and engaging in argumentation.

Another implication is the role of the teacher in enabling an explicit literacy instruction on scientific genres. Gillies and Baffour (2017, p.495) argue that "teachers play a key role in constructing learning situations where students have opportunities to learn the language of science." We extend this argument further to include not only the language of science, but also its metalanguage. As most teachers are not familiar with the metalanguage of scientific genres, it will imply some form of teacher education is required to prepare them for introducing scientific metalanguage to their students. In this study, it was through the professional development workshops that the participating teachers learned and subsequently implemented the PRO metalanguage in their classrooms. Although these aspects of teacher education and implementation fidelity are not emphasized in this study, there is evidence

\footnotetext{
${ }^{1}$ Science teachers often make a distinction between describe and explain to their students, whereby "explain" usually requires more elaboration and a higher Bloom's Taxonomy cognitive level. However, such distinction is vague and oversimplified and only emphasizes the level of thinking required, particularly for assessment purpose. It does not delve into the language and social practices that account for the difference between informational report (description) and explanation.
} 
CITATION: Tang, K.S. \& Rappa, N.A. (2020). The Role of Metalanguage in an Explicit Literacy Instruction on Scientific Explanation. International Journal of Science and Mathematics Education. doi: 10.1007/s10763-02010121-6.

from the classroom discourse that indicate the teachers' adaptability and resourcefulness in integrating the PRO metalanguage into their classroom practices. As such, this study provides an encouraging sign that points to future possibilities of preparing science teachers to implement effective classroom talk about scientific genres through the use of a metalanguage.

The distinction between an implicit and explicit form of literacy instruction highlighted in this study also has implications on what counts as a pedagogical content knowledge (PCK; Shulman, 1986), as opposed to content knowledge (CK) and pedagogical knowledge $(\mathrm{PK})$. The science teachers in our study had the $\mathrm{CK}$ of a scientific explanation in terms of its features (e.g., sequences, keywords) and PK of facilitating student to learn explanations through generic strategies like questioning. However, the inability to translate these $\mathrm{CK}$ and PK and explicitly teach the nature of scientific explanation suggests a lack of PCK to do so. The role of a metalanguage could be a crucial factor in enabling science teachers to gain this specific PCK. This aspect of PCK aligns well with the notion of literacy pedagogical content knowledge (LPCK) first proposed by Love (2010) to take into consideration the role of language and literacy in content-area teaching.

Besides classroom talk, there are also different teaching methods that can be used to incorporate metalanguage to provide explicit literacy instruction. In this paper, the main literacy activity centered on classroom discourse, particularly whole-class discussion involving the PRO metalanguage. This focus on whole-class discussion was largely a result of the design research project and the corresponding data collection methods focusing on the teacher. Nevertheless, the role of a metalanguage in facilitating an explicit literacy instruction can also be enacted through other literacy activities such as reading, writing, and student discussion. In another study, we have examined how the students used the PRO metalanguage to scaffold their writing (Putra \& Tang, 2016). Future research could focus on 
CITATION: Tang, K.S. \& Rappa, N.A. (2020). The Role of Metalanguage in an Explicit Literacy Instruction on Scientific Explanation. International Journal of Science and Mathematics Education. doi: 10.1007/s10763-02010121-6.

how metalanguage could be incorporated into reading activity and student group discussion.

Regardless of the different literacy activities, explicit literacy instruction should involve a metalanguage to unpack and bring to awareness the unspoken conventions that are embedded in genres.

Last but not least, the purpose of using metalanguage to make explicit the conventions of genres is not to impose rules or create rigid standards for students to follow. Instead, the purpose is to empower students to see and understand that every discipline (including science) is a form of discourse with a particular socio-historical system of knowledge and practice (Gee, 2004). This critical view of literacy is aligned with the New London Group's (1996) multiliteracies pedagogy, which consists of four aspects: situated practice, overt instruction, critical framing, and transformed practice. Situated practice is the immersion of the learning experience within a meaningful and authentic context. In this study, situated practice was provided through the literacy-inquiry model, which was designed to present real-world phenomena in interesting ways before the students explained those phenomena. In overt instruction, explicit instructional support must be provided for the students to develop an awareness of and control over the discourse through its genres. The emphasis on metalanguage in this paper is an example of overt instruction.

According to multiliteracies pedagogy, overt instruction is necessary in order for the students to further develop critical framing and transformed practice, which will involve the ability to interpret the social and cultural context of science and constructively critique and adapt it for personal use. For example, an important component of science education is to help students understand the rationale of how scientific knowledge is produced, legitimized, and communicated according to specific genres instead of imagining an overly simplistic "scientific method." Therefore, learning and incorporating the metalanguage of the various genres within a discipline will facilitate students to develop a deep epistemic understanding 
CITATION: Tang, K.S. \& Rappa, N.A. (2020). The Role of Metalanguage in an Explicit Literacy Instruction on Scientific Explanation. International Journal of Science and Mathematics Education. doi: 10.1007/s10763-02010121-6.

of the discipline. We argue that the use of scientific metalanguage during explicit literacy

instruction provides an important foundation for this critical aspect of scientific literacy.

\section{References}

Abrahams, I., Reiss, M. J., \& Sharpe, R. M. (2013). The assessment of practical work in school science. Studies in Science Education, 49(2), 209-251. doi:10.1080/03057267.2013.858496

Achinstein, P. (1983). The nature of explanation. New York: Oxford University Press.

Andringa, S., de Glopper, K., \& Hacquebord, H. (2011). Effect of explicit and implicit instruction on free written response task performance. Language Learning, 61(3), 868-903. doi:doi:10.1111/j.1467-9922.2010.00623.x

Barber, J., Pearson, D., \& Cervetti, G. (2006). Seeds of science/roots of reading. California: The Regents of the University of California.

Basturkmen, H., Loewen, S., \& Ellis, R. (2002). Metalanguage in focus on form in the communicative classroom. Language Awareness, 11(1), 1-13. doi:10.1080/09658410208667042

Braaten, M., \& Windschitl, M. (2011). Working toward a stronger conceptualization of scientific explanation for science education. Science Education, 95, 639-669. doi: $10.1002 /$ sce. 20449

Brown, P. L., \& Concannon, J. P. (2016). Students' perceptions of vocabulary knowledge and learning in a middle school science classroom. International Journal of Science Education, 38(3), 391-408. doi:10.1080/09500693.2016.1143571

Bruna, K. R., Vann, R., \& Escudero, M. P. (2007). What's language got to do with it?: A case study of academic language instruction in a high school "English Learner Science" class. Journal of English for Academic Purposes, 6(1), 36-54.

Cavagnetto, A. R. (2010). Argument to foster scientific literacy: A review of argument interventions in K-12 science contexts. Review of Educational Research, 80(3), 336371.

Chin, C. (2006). Classroom interaction in science: Teacher questioning and feedback to students' responses. International Journal of Science Education, 28(11), 1315-1346. doi:10.1080/09500690600621100

Collins, A., Joseph, D., \& Bielaczyc, K. (2004). Design research: Theoretical \& methodological Issues. Journal of Learning Sciences, 13(1), 15-42.

Council of Chief State School Officers. (2010). Common Core State Standards. Washington D.C.: National Governors Association Center for Best Practices, Council of Chief State School Officers.

Denzin, N. K. (2002). Interpretive interactionism (2nd ed.). London: Sage.

Erduran, S., Simon, S., \& Osborne, J. (2004). TAPping into argumentation: Developments in the application of Toulmin's Argument Pattern for studying science discourse. Science Education, 88(6), 915-933. doi:10.1002/sce.20012

Erickson, F. (1992). Ethnographic microanalysis of interaction. In M. D. LeCompte, W. Millroy, \& J. Preissle (Eds.), The handbook of qualitative research in education (pp. 201-225). New York: Academic Press.

Fairclough, N. (1992). Discourse and social change. Cambridge, M.A.: Polity Press.

Fang, Z., Lamme, L. L., \& Pringle, R. M. (2010). Language and literacy in inquiry-based science classrooms, grades 3-8. Thousand Oaks, CA: Corwin Press. 
CITATION: Tang, K.S. \& Rappa, N.A. (2020). The Role of Metalanguage in an Explicit Literacy Instruction on Scientific Explanation. International Journal of Science and Mathematics Education. doi: 10.1007/s10763-02010121-6.

Ford, M. J. (2015). Educational implications of choosing "practice" to describe science in the Next Generation Science Standards. Science Education, 99(6), 1041-1048. doi: $10.1002 /$ sce. 21188

Garcez, P. M. (2017). Microethnography in the Classroom. In K. A. King, Y.-J. Lai, \& S. May (Eds.), Research Methods in Language and Education (pp. 435-447). Cham: Springer International Publishing.

Gee, J. P. (2004). Language in the science classroom: Academic social languages as the heart of school-based literacy. In W. Saul (Ed.), Crossing borders in literacy and science instruction: Perspectives on theory and practice (pp. 13-32). Newark, DE: NSTA Press.

Gee, J. P. (2010). An introduction to discourse analysis : theory and method (Third ed.). London: Routledge.

Gillies, R. M., \& Baffour, B. (2017). The effects of teacher-introduced multimodal representations and discourse on students' task engagement and scientific language during cooperative, inquiry-based science. Instructional Science, 45(4), 493-513. doi:10.1007/s11251-017-9414-4

Guthrie, J. T., Wigfield, A., \& Perencevich, K. C. (Eds.). (2004). Motivating reading comprehension: Concept-Oriented Reading Instruction. Mahwah, NJ: Erlbaum.

Halliday, M. A. K. (1993). On the language of physical science. In M. A. K. Halliday \& J. R. Martin (Eds.), Writing science: Literacy and discursive power (pp. 54-68). Pittsburgh: University of Pittsburgh Press.

Halliday, M. A. K., \& Matthiessen, C. M. I. M. (2004). An introduction to functional grammar (3rd ed.). London: Arnold.

Hand, B., Shelley, M. C., Laugerman, M., Fostvedt, L., \& Therrien, W. (2018). Improving critical thinking growth for disadvantaged groups within elementary school science: A randomized controlled trial using the Science Writing Heuristic approach. Science Education, 102(4), 693-710. doi:10.1002/sce.21341

Lemke, J. L. (1990). Talking science: language, learning and values: Norwood, NJ: Ablex.

Love, K. (2010). Literacy pedagogical content knowledge in the secondary curriculum. Pedagogies: An International Journal, 5(4), 338-355.

Martin, J. R. (2007). Genre, ideology and intertextuality: a systemic functional perspective. Linguistics and the Human Sciences, 2(2), 275.

Martin, J. R., \& Rose, D. (2007). Working with discourse : meaning beyond the clause (2nd ed.). London: Continuum.

Mitchell, J. C. (1983). Case and situation analysis. Sociological Review, 31, 187-211.

Moje, E. B. (2007). Developing socially just subject-matter instruction: a review of the literature on disciplinary literacy teaching. Review of Research in Education, 31, 1-44.

Mortimer, E. F., \& Scott, P. (2003). Meaning making in secondary science classrooms. Buckingham, England: Open University Press.

National Research Council. (2012). A framework for K-12 science education: Practices, crosscutting concepts, and core ideas. Washington, DC: The National Academies Press.

New London Group. (1996). A pedagogy of multiliteracies: Designing social futures. Harvard Educational Review, 66, 60-92.

Norris, S. P., \& Phillips, L. M. (1994). Interpreting pragmatic meaning when reading popular reports of science. Journal of research in science teaching, 31(9), 947-967. doi:doi:10.1002/tea.3660310909

Norris, S. P., Phillips, L. M., Smith, M. L., Guilbert, S. M., Stange, D. M., Baker, J. J., \& Weber, A. C. (2008). Learning to read scientific text: Do elementary school 
CITATION: Tang, K.S. \& Rappa, N.A. (2020). The Role of Metalanguage in an Explicit Literacy Instruction on Scientific Explanation. International Journal of Science and Mathematics Education. doi: 10.1007/s10763-02010121-6.

commercial reading programs help? Science Education, 92(5), 765-798. doi:doi:10.1002/sce.20266

Pearson, P. D., Moje, E., \& Greenleaf, C. (2010). Literacy and science: Each in the service of the other. Science, 328(5977), 459-463. doi:10.1126/science.1182595

Putra, G. B. S., \& Tang, K.-S. (2016). Disciplinary literacy instructions on writing scientific explanations: A case study from a chemistry classroom in an all-girls school. Chemistry Education Research and Practice, 17(3), 569-579. https://doi.org/10.1039/c6rp00022c

Robertson, A. D., \& Elliott, L. J. A. (2020). Truth, success, and faith: Novice teachers' perceptions of what's at risk in responsive teaching in science. Science Education, 26. doi: $10.1002 /$ sce. 21568

Sampson, V., Grooms, J., \& Walker, J. P. (2011). Argument-driven inquiry as a way to help students learn how to participate in scientific argumentation and craft written arguments: An exploratory study. Science Education, 95(2), 217-257. doi:doi:10.1002/sce.20421

Schleppegrell, M. (2013). The role of metalanguage in supporting academic language development. Language Learning, 63(1), 153-170.

Shanahan, M. C. (2012). Reading for evidence through hybrid adapted primary literature. In S. P. Norris (Ed.), Reading for evidence and interpreting visualizations in mathematics and science education (pp. 41-63). Rotterdam: SensePublishers.

Shulman, L. S. (1986). Those who understand: Knowledge growth in teaching. Educational researcher, 15(2), 4-14.

Sørvik, G. O., Blikstad-Balas, M., \& Ødegaard, M. (2015). "Do books like these have authors?" New roles for text and new demands on students in integrated scienceliteracy instruction. Science Education, 99(1), 39-69. doi:10.1002/sce.21143

Stake, R. E. (2000). Case studies. In N. Denzin \& Y. Lincoln (Eds.), Handbook of qualitative research (2nd ed., pp. 435-454). London: Sage.

Tang, K.-S. (2016a). How is disciplinary literacy addressed in the science classrooms? A Singaporean case study. Australian Journal of Language and Literacy, 39(3), 220232.

Tang, K.-S. (2016b). Constructing scientific explanations through premise-reasoningoutcome (PRO): An exploratory study to scaffold students in structuring written explanations. International Journal of Science Education, 38(9), 1415-1440. https://doi.org/10.1080/09500693.2016.1192309

Tang, K.-S., \& Danielsson, K. (Eds.). (2018). Global Developments in Literacy Research for Science Education. Cham, Switzerland: Springer. https://doi.org/10.1007/978-3-31969197-8

Tang, K.-S., \& Putra, G. B. S. (2018). Infusing literacy into an inquiry instructional model to support students' construction of scientific explanations. In K. S. Tang \& K. Danielsson (Eds.), Global developments in literacy research for science education (pp. 281-300). Cham, Switzerland: Springer

Tang, K.-S. (2019). The role of language in scaffolding content \& language integration in CLIL science classrooms. Journal of Immersion and Content-Based Language Education, 7(2), 315-328. https://doi. org/10.1075/jicb.00007.tan

Toulmin, S. E. (1958). The uses of argument. Cambridge, England: Cambridge University Press.

Unsworth, L. (2001). Evaluating the language of different types of explanations in junior high school science texts. International Journal of Science Education, 23(6), 585-609.

Vygotsky, L. (1986). Thought and language (Translation newly rev. and edited / by Alex Kozulin ed.). Cambridge, MA: MIT Press. 
CITATION: Tang, K.S. \& Rappa, N.A. (2020). The Role of Metalanguage in an Explicit Literacy Instruction on Scientific Explanation. International Journal of Science and Mathematics Education. doi: 10.1007/s10763-02010121-6.

Wellington, J., \& Osborne, J. (2001). Language and literacy in science education. Philadelphia, PA: Open University Press.

Wilson, A., \& Jesson, R. (2018). A case study of literacy teaching in six middle- and highschool science classes in New Zealand. In K.-S. Tang \& K. Danielsson (Eds.), Global Developments in Literacy Research for Science Education (pp. 133-147). Cham, Switzerland: Springer.

Wright, K. L., Franks, A. D., Kuo, L.-J., McTigue, E. M., \& Serrano, J. (2016). Both theory and practice: Science literacy instruction and theories of reading. International Journal of Science and Mathematics Education, 14(7), 1275-1292. doi:10.1007/s10763-015-9661-2

Yang, X., Kuo, L.-J., \& Jiang, L. (2020). Connecting theory and practice: a systematic review of K-5 science and math literacy instruction. International Journal of Science and Mathematics Education, 18(2), 203-219. doi:10.1007/s 10763-019-09957-4

Yore, L. D. (2018). Commentary on the expanding development of literacy research in science education. In K. S. Tang \& K. Danielsson (Eds.), Global developments in literacy research for science education. Cham, Switzerland: Springer. 